\title{
Elaboração de Documentos Psicológicos: Considerações Críticas à Resolução CFP n007/2003
}

\author{
Vivian de Medeiros Lago ${ }^{1}$ \\ Universidade do Vale do Rio dos Sinos, São Leopoldo, RS, Brasil \\ Faculdades Integradas de Taquara, Taquara, RS, Brasil \\ Denise Balem Yates \\ Centro de Avaliação Psicológica da Universidade Federal do Rio Grande do Sul, \\ Porto Alegre, RS, Brasil \\ Denise Ruschel Bandeira \\ Instituto de Psicologia da Universidade Federal do Rio Grande do Sul, \\ Porto Alegre, RS, Brasil
}

\begin{abstract}
Resumo
O presente artigo tem como objetivo discutir o conteúdo da Resolução n 007/2003 do Conselho Federal de Psicologia, que trata sobre a elaboração de documentos psicológicos escritos e que teve como intuito reduzir o número de queixas a sua qualidade. Contudo, o que se observa nos dias atuais é que ainda existem muitos processos éticos decorrentes de falhas em documentos, especialmente em laudos/ relatórios psicológicos. A grande heterogeneidade desses documentos, tanto em termos de forma quanto de conteúdo, pode suscitar dúvidas acerca de sua qualidade. Os comentários e críticas desenvolvidos neste texto pretendem auxiliar os profissionais na produção de seus documentos, e também servir como uma referência atualizada sobre essa temática, visando contribuir para a produção de documentos de boa qualidade. São abordados os princípios técnicos da linguagem escrita, assim como os princípios éticos, técnicos e científicos da profissão. A importância da devolução por escrito dos resultados das avaliações, juntamente com a devolução oral obrigatória, também é apontada. As quatro modalidades de documentos psicológicos são apresentadas, por meio da discussão de seus objetivos e estruturas, com sugestões de acréscimos à estrutura do laudo/relatório. Por fim, algumas orientações práticas para a escrita de documentos são oferecidas.
\end{abstract}

Palavras-chave: Avaliação psicológica, laudos psicológicos, ética profissional.

\section{Psychological Reports Writing: Critical Considerations to CFP Resolution 07/2003}

\begin{abstract}
This article aims to discuss the content of Resolution $N^{\circ}$ 007/2003 of the Federal Council of Psychology, which comprised psychological reports' writing and had the intention to reduce the number of complaints to their quality. However, nowadays there are still many ethical processes due to faults in these documents, especially in psychological reports. The great heterogeneity of these documents, both in terms of form and content, may raise doubts about their quality. The comments and criticisms developed in this paper are intended to assist professionals in the writing of their documents, and also
\end{abstract}

Endereço para correspondência: Travessa Alexandrino de Alencar, 50 / 701 A, Azenha, Porto Alegre, RS, Brasil 90160-030. Fone: (51) 9323-5382. E-mail: vmlago@gmail.com 
serve as an updated reference on this topic, in order to contribute to the improvement of the quality of the documents. The paper examines the technical principles of written language, as well as the ethical, technical and scientific principles of the profession of psychologist. The importance of a written return of the results of evaluations, along with the obligatory oral return is also highlighted. The four types of psychological documents are presented, as well as the discussion of their goals and structures, with suggestions for additions to the report structure. Finally, some practical guidelines for writing documents are offered.

Keywords: Psychological assessment, psychological finds, professional ethics.

\section{Elaboración de Documentos Psicológicos: Consideraciones Críticas a la Resolución CFP 07/2003}

\section{Resumen}

Este artículo objetiva discutir el contenido de la Resolución $N^{\circ}$ 007/2003 del Consejo Federal de Psicología, que se ocupa de la preparación de documentos escritos psicológicos e intentaba reducir el número de denuncias a la calidad de estos. Sin embargo, lo que se observa actualmente es que todavía hay muchos procesos éticos de fallas en los informes psicológicos. La gran heterogeneidad de estos documentos, tanto en términos de forma y contenido, puede plantear dudas sobre su calidad. Los comentarios y críticas desarrollados en este trabajo están destinados a ayudar a los profesionales en la producción de sus documentos, y sirven como una referencia actualizada para contribuir a la mejora de la calidad de documentos. El trabajo examina los principios técnicos de la lengua escrita, así como los principios éticos, técnicos y científicos de la profesión de psicólogo. La importancia de la devolución de forma escrita de los resultados de las evaluaciones, además de la devolución oral obligatoria, es destacada. Se presentan los cuatro tipos de documentos psicológicos, a través de la discusión de sus objetivos y estructuras, con sugerencias para adiciones a la estructura del informe psicológico. Por último, se ofrecen algunas directrices prácticas para la redacción de documentos.

Palabras clave: Evaluación psicológica, hallasgos psicológicos, ética profesional.

O resultado de uma avaliação psicológica deveria ser comumente registrado por meio de diferentes documentos, de acordo com seus propósitos. Entretanto, questões como a formação profissional e a subjetividade do examinador, presentes nas avaliações psicológicas, resultam em uma heterogeneidade de documentos, tanto em termos de forma quanto de conteúdo. Essa falta de um padrão mais homogêneo pode suscitar dúvidas acerca de sua qualidade. Ademais, muitos processos éticos são desencadeados em decorrência da baixa qualidade de laudos e pareceres.

Com o objetivo de fornecer diretrizes para os profissionais, garantindo maior uniformidade e qualidade na produção desses documentos, o Conselho Federal de Psicologia (CFP) elaborou a Resolução CFP n 30/2001, posteriormente revogada pela Resolução CFP $n^{\circ}$ 17/2002, também revogada em seguida, pela Resolução CFP $n^{\circ}$ 007/2003 (2003b). Essas resoluções instituíram o Manual de Elaboração de Documentos Escritos produzidos pelo psicólogo, decorrentes de avaliação psicológica. A normativa de 2003 é a referência mais atualizada de que os psicólogos dispõem para a produção de documentos escritos. Shine (2009) inclusive aponta que a rapidez com que as revogações foram produzidas leva a crer que há muita dificuldade em se chegar a um consenso satisfatório nesse campo. $\mathrm{O}$ autor destaca, ainda, que desde a criação da primeira Resolução (n $\left.{ }^{\circ} 30 / 2001\right)$, o intuito era o de diminuir o número crescente de queixas à qualidade dos documentos psicológicos. Contudo, o que se observa nos dias atuais é que ainda existem muitos processos éticos decorrentes de falhas em 
documentos, especialmente em laudos/relatórios psicológicos. Para ilustrar, conforme dados de registros do CFP, no ano de 2013, 11 dos 50 processos éticos que chegaram ao CFP em grau recursal, relacionavam-se a falhas em documentos produzidos na área da Psicologia Jurídica, em que a comunicação se dá de forma escrita e, consequentemente, mais suscetível a ações judiciais. Diante deste fato, justifica-se a produção deste artigo, cujo escopo é o de discutir o conteúdo da Resolução CFP n 007/2003 (2003b), tecendo comentários e críticas, com o objetivo de auxiliar os profissionais na elaboração de seus documentos. Nossa proposta com este trabalho advém, também, da carência de referências atualizadas sobre a temática de documentos psicológicos. Na condição de professoras de cursos de graduação, extensão e pós-graduação, frequentemente trabalhamos com a elaboração dos documentos em sala de aula e nos deparamos com a dificuldade de encontrar materiais complementares à Resolução para orientar os alunos. Espera-se, assim, que as ideias aqui discutidas possam servir como um material de apoio didático, proporcionando críticas reflexivas e atingindo, por consequência, nosso objetivo maior, que é o de contribuir para o aprimoramento da formação dos psicólogos por meio da produção de documentos de boa qualidade.

O Manual de Elaboração de Documentos Escritos dispõe sobre os seguintes itens: princípios norteadores; modalidades de documentos; conceito/finalidade/estrutura; validade e guarda dos documentos. O Manual informa, ainda, que toda e qualquer comunicação por escrito decorrente de avaliação psicológica deverá seguir as orientações nele dispostas; caso contrário, o psicólogo estará incorrendo em falta ético disciplinar. Cabe, pois, o primeiro comentário à referida Resolução: observa-se, a partir das disposições iniciais, a relevância deste manual, sendo esperado o seu conhecimento por parte de todos os psicólogos, especialmente os que atuam na área de avaliação psicológica. Entretanto, o que as autoras observam a partir de sua prática docente, especialmente em cursos de extensão e de especialização, é um desconhecimento por parte de muitos profissionais acerca dessa Resolução. Ao ministrar aulas sobre elaboração de documentos, principalmente para alunos que já concluíram sua graduação há mais tempo, percebe-se que o manual é visto por muitos como uma novidade. Entendemos que falhas na formação em Psicologia podem gerar esse tipo de desconhecimento. No entanto, considerando-se a necessidade de os profissionais manterem-se atualizados em sua prática profissional, mesmo afastados de cursos formais, aliada ao fato de que a resolução já existe há pelo menos dez anos, pressupõe-se que muitos psicólogos não têm o hábito de verificar as Resoluções emitidas pelo CFP e disponibilizadas em seu site (www.cfp.org.br). Uma sugestão seria uma divulgação mais enfática do Sistema Conselhos quanto às aplicações das resoluções, na forma de cartilhas ou outros materiais didáticos.

Esse desconhecimento ajuda-nos a compreender o alto número de processos éticos decorrentes da má qualidade de documentos. Nesse sentido, têm-se os dados do estudo realizado por Frizzo (2004) sobre as principais infrações éticas cometidas pelos psicólogos inscritos no Conselho Regional 12 no período de 1994 a 2003. Seus resultados evidenciaram que $46,15 \%$ das infrações denunciadas a este Conselho Regional referiam-se a falhas na realização de perícia e/ou avaliação psicológica.

\section{Princípios Norteadores}

Dentre os princípios norteadores da elaboração de documentos, a Resolução destaca as técnicas da linguagem escrita e os princípios éticos, técnicos e científicos da profissão. É importante que os documentos apresentem uma linguagem clara, correta, com encadeamento de ideias, permitindo a comunicação e compreensão do trabalho técnico exposto. Reforça-se essa orientação da Resolução, pois inadequações no uso da expressão escrita formal desvalorizam os documentos produzidos pelo psicólogo, uma vez que não sabemos se é uma falha na formação do profissional ou na sua capacidade de expressão. Da mesma forma, problemas na estrutura frasal e/ou ordenamento adequado dos conteúdos podem levar a entendimentos errôneos acerca do 
que se quer transmitir, podendo trazer consequências negativas para os avaliados, considerando especialmente a quem o documento é destinado. Por exemplo, no contexto organizacional erros de redação podem levar um gestor a demitir um funcionário.

Cruz (2002) enfatiza que a linguagem utilizada deve ser objetiva, coerente e consistente. É importante que o conteúdo do documento seja claro o suficiente para o melhor entendimento do requerente e, para tanto, é necessária uma organização dos argumentos, acompanhada de capacidade teórica e conceitual. O autor ainda aponta a importância de se evitar juízo de valor e dogmas, resguardando a coerência interna na redação do documento e, apresentando correlações técnicas entre a metodologia utilizada e a comunicação dos resultados obtidos a partir dos procedimentos utilizados. Nesse sentido, ele também cita exemplos de incorreções teóricas e técnicas ("falta maturidade"; "não dispõe de recursos intelectuais") e de impropriedade na escrita e no uso de termos ("mostra falsas reações"; "seu desempenho na avaliação foi muito razoável"). Cunha (2000), no que tange ainda à questão da linguagem, aponta que o conteúdo dos documentos deve estar apropriado a seu destinatário, isto é, deve respeitar características como nível sociocultural, intelectual e emocional daquele a quem será endereçado o laudo ou parecer. A autora ressalta que a expressão escrita do documento é definida pela identidade e qualidade de seu destinatário, ou seja, um mesmo psicólogo pode escrever diferentes documentos com níveis de profundidades teórico-técnicas diversas. Isso não desmerece a qualidade do seu documento.

No que diz respeito aos princípios éticos, o psicólogo deve observar os dispositivos do Código de Ética Profissional do Psicólogo (Resolução CFP $n^{\circ}$ 010/2005), atentando a questões como o sigilo profissional, as relações com a justiça e o alcance das informações prestadas. O Código atual data de 2005 e tem como objetivo principal estabelecer um padrão de conduta esperado para as práticas da categoria. Sendo assim, coloca alguns pontos de orientação im- portantes para os profissionais, bem como incentiva a autorreflexão do psicólogo sobre algumas questões, buscando responsabilizá-lo, pessoal e coletivamente, por ações e suas consequências no exercício profissional.

Dentre os deveres fundamentais dos psicólogos (Resolução CFP no 010/2005), segundo o Código de Ética ( $\operatorname{artigo} 1^{\circ}$ ), destacam-se o dever de informar, a quem de direito, somente os resultados da prestação de serviços psicológicos necessários para a tomada de decisões que afetem o usuário ou beneficiário (artigo $1^{\circ}$, alínea g) e o dever de orientar, a quem de direito, sobre os encaminhamentos apropriados e fornecer, sempre que solicitado, os documentos pertinentes ao bom termo do trabalho (artigo $1^{\circ}$, alínea $h$ ). Ambos os deveres ressaltam a importância de fornecer informações sobre os serviços prestados, ao mesmo tempo resguardando-as ao mínimo necessário. Por outro lado, estes dispositivos não deixam explícito se há a obrigatoriedade do fornecimento de documentos escritos como forma de devolução dos serviços de avaliação psicológica.

Em função desta falta de clareza, podem-se buscar outros referenciais éticos para refletir acerca da necessidade ou não do fornecimento de documentos escritos como resultado da avaliação psicológica. Os princípios éticos que orientam a pesquisa com seres humanos e que influenciam vários códigos de ética das ciências humanas e da saúde são denominados respeito, beneficência/não maleficência e justiça, tendo sido sistematizados pela primeira vez pelo Belmont Report: Ethical Principles and Guidelines for the Protection of Human Subjects of Research (The National Commission for the Protection of Human Subjects of Biomedical and Behavioral Research, 1979). Considerando que o princípio da beneficiência/não maleficiência preconiza não causar o mal, maximizar os benefícios possíveis e minimizar os danos possíveis, coloca-se a questão sobre o que beneficiaria mais o paciente avaliado: a devolução apenas oral ou a devolução oral acompanhada pelo documento escrito.

Em nossa prática, observamos que muitos pacientes que buscam uma avaliação psicológica 
realizaram avaliações anteriores, mas não sabem reportar com exatidão o que lhes foi informado a respeito. Tal fato pode demonstrar a falta de compreensão dos pacientes acerca do que lhe foi devolvido, bem como dificuldades de guardar na memória informações técnicas que por vezes datam de vários anos. Se a avaliação psicológica é considerada um instrumental psicológico, ela deveria funcionar como o resultado de um exame, o qual deve ser registrado por escrito para comparações posteriores. Certamente é necessário que exista uma flexibilidade a respeito do tipo de informes escritos a serem fornecidos aos diferentes destinatários (profissional que encaminhou o paciente para avaliação, próprio paciente ou familiar, profissionais da área da educação ou trabalho que convivem com o paciente), mas é importante que exista alguma forma de registro acerca do que foi observado no período da avaliação psicológica. Tal como afirmamos acima: a forma do documento é definida pela identidade e qualidade de seu receptor (Cunha, 2000).

Diversos psicólogos afirmam que o não fornecimento de documentos escritos se deve à preocupação com potenciais usos indevidos das informações contidas nesses informes. Muitos temem que ocorra uma exposição de dados sigilosos a respeito dos pacientes. Como forma de evitar este risco, vários profissionais e instituições colocam-se à disposição para serem contatados no futuro a respeito dos pacientes, mas se negam a produzir qualquer registro escrito. No entanto, ao negarem o fornecimento de informações escritas, muitas vezes os profissionais estão negando o acesso dos pacientes e profissionais de saúde aos resultados da avaliação, tendo em vista que muitos pacientes perdem o contato com psicólogos anteriores; além disso, nem sempre os profissionais que atenderão esses pacientes estarão dispostos a entrar em contato.

Hutz (2009) também relaciona o direito que os indivíduos têm de conhecer os resultados de suas avaliações, suas implicações e o uso que poderá ser feito dos dados coletados ao princípio ético do respeito. $\mathrm{O}$ autor ressalta que o atual Código de Ética da American Psychological Association (APA, 2002) garante aos indivíduos o direito de ter acesso irrestrito ao seu prontuário e a todos os resultados de avaliações psicológicas. No Brasil, ainda temos como orientação complementar a Resolução CFP n ${ }^{0} 001 / 2009$, que dispõe sobre a obrigatoriedade do registro documental decorrente da prestação de serviços psicológicos. A referida normativa aponta que os registros sobre a prestação de serviços psicológicos têm caráter sigiloso e devem ser permanentemente atualizados e organizados pelo profissional que acompanha o procedimento. Garante, ainda, ao paciente, ou seu representante legal, o acesso integral às informações registradas, da mesma forma que o Código da APA. Nesse sentido, consideramos que seria necessária a inclusão da obrigatoriedade de fornecimento dos documentos escritos aos interessados em futuras resoluções.

No que se refere aos princípios técnicos e científicos dos documentos psicológicos escritos, é importante considerar as variáveis históricas, sociais, econômicas e políticas do processo de avaliação, que tornam o processo de avaliação psicológica de natureza dinâmica e não definitiva. Nesse sentido, Silva (2006) salienta que o psicólogo deve fazer constar no documento psicológico (laudo ou parecer) que os dados descritos dizem respeito ao estado psicológico do avaliado naquele momento, não podendo ser considerados definitivos ou imutáveis. Tavares (2012) comenta a complexidade da avaliação psicológica, que é um produto de sua demanda, da compreensão que o avaliador tem sobre ela e os objetivos que traça para desenvolver o processo. Além dessas condições iniciais, o autor destaca também a influência do contexto de vida do indivíduo e da qualidade da relação entre avaliador e avaliado para o resultado final da avaliação. Esses aspectos integram os princípios técnicos descritos na Resolução CFP n ${ }^{\circ}$ 007/2003 (2003b), uma vez que permitem evidenciar a natureza dinâmica da avaliação, influenciada pelas circunstâncias do momento e da dinâmica da avaliação.

A Resolução orienta, ainda nos princípios técnicos, que os documentos sejam baseados exclusivamente em instrumentais técnicos que 
se configurem como métodos e técnicas psicológicas. São citados, como exemplos, entrevistas, testes, observações, dinâmicas de grupo, escuta e intervenções verbais. Entendemos, a partir dessa orientação, é que outras técnicas, que não exclusivamente os testes psicológicos, possam ser utilizadas para compor o entendimento do caso sob avaliação. Podem ser mencionadas como exemplos escalas psiquiátricas, como a SCID (Structured Clinical Interview for DSM; Del-Ben et al., 2001) e o Mini Exame do Estado Mental (Folstein, Folstein, \& McHugh, 1975), bastante utilizadas em avaliações que demandam um diagnóstico nosológico. Na área da avaliação de leitura e escrita, podemos citar o Teste de Desempenho Escolar (TDE; Stein, 1994) e o PROLEC (Provas de Avaliação dos Processos de Leitura; Capellini, Oliveira, \& Cuetos, 2010), utilizados por educadores e fonoaudiólogos. O TDE consta, inclusive, na lista de instrumentos de uso não privativo do psicólogo do SATEPSI (Sistema de Avaliação de Testes Psicológicos). O SARP (Sistema de Avaliação do Relacionamento Parental; Lago \& Bandeira, 2013), recentemente lançado, é outro exemplo de método de avaliação que não se enquadra nos critérios de teste psicológico descritos na Resolução CFP $n^{\circ}$ 002/2003 (2003a), mas que pode embasar um laudo, por configurar-se como um instrumental técnico do psicólogo. Esse assunto merece uma discussão mais profunda no âmbito da categoria profissional, contudo transcende o escopo deste artigo. Uma vez tendo discutido os princípios norteadores do Manual de Elaboração de Documentos Escritos, passaremos à análise das modalidades de documentos dispostas na Resolução CFP n ${ }^{\circ}$ 007/2003 (2003b) do CFP. Por se tratarem de documentos mais simples em sua elaboração, a declaração e o atestado serão brevemente apresentados e discutidos, sendo priorizada a discussão dos laudos/relatórios e pareceres psicológicos. É valido apontar, ainda, a observação feita na Resolução de que "a declaração e o parecer psicológico não são documentos decorrentes da avaliação psicológica, embora muitas vezes apareçam desta forma" (p. 5). Comentários nesse sentido serão abordados quando da discussão de cada modalidade de documento.

\section{Modalidades de Documentos}

\section{Declaração e Atestado Psicológico}

Quatro são as modalidades de documentos previstas na Resolução CFP $n^{\circ}$ 007/2003: declaração, atestado, relatório/laudo e parecer psicológico. A declaração

visa informar a ocorrência de fatos ou situações objetivas relacionadas ao atendimento psicológico, com a finalidade de declarar: a) Comparecimentos do atendido e/ou do seu acompanhante, quando necessário; b) Acompanhamento psicológico do atendido; c) Informações sobre as condições do atendimento (tempo de acompanhamento, dias ou horários). Neste documento não deve ser feito o registro de sintomas, situações ou estados psicológicos. (2003b, p. 5)

Já o atestado

certifica uma determinada situação ou estado psicológico, tendo como finalidade afirmar sobre as condições psicológicas de quem, por requerimento, o solicita, com fins de: a) Justificar faltas e/ou impedimentos do solicitante; b) Justificar estar apto ou não para atividades específicas, após realização de um processo de avaliação psicológica, dentro do rigor técnico e ético que subscreve esta Resolução; c) Solicitar afastamento e/ou dispensa do solicitante, subsidiado na afirmação atestada do fato, em acordo com o disposto na Resolução CFP $\mathrm{n}^{\circ}$ 015/96. (Resolução CFP no 007/2003, 2003b, p. 6)

Apesar da distinção entre Declaração e Atestado, frequentemente se observa a solicitação equivocada, por parte dos avaliados, de emissão de atestados para justificar faltas ou afastamentos do trabalho para comparecimento à avaliação psicológica. Na verdade, a mera justificativa de falta ou afastamento do trabalho, sem registro de sintomas ou estados psicológicos, implicaria a produção de uma declaração, e não de um atestado. É responsabilidade do profissional saber qual o tipo de documento deverá produzir diante de um pedido desses e esclarecer ao solicitante. 
Os psicólogos dispõem, também, da Resolução CFP n $15 / 1996$, que institui e regulamenta a Concessão de Atestado Psicológico para tratamento de saúde por problemas psicológicos. Essa informação é outro exemplo de dúvida frequente entre os psicólogos, os quais possivelmente desconhecem essa possibilidade, acreditando que apenas os médicos podem emitir atestados para afastamento em virtude de problemas de saúde.

O parágrafo único do artigo $1^{\circ}$ dessa resolução (Resolução CFP n¹5/1996) dispõe sobre o fato de ser facultado ao psicólogo utilizar o Código Internacional de Doenças (CID) como fonte de enquadramento de diagnóstico nos atestados. No artigo $2^{\circ}$, da referida Resolução, há a orientação de que o psicólogo, ao emitir atestado com a finalidade de afastamento para tratamento de saúde, deva manter em seus arquivos a documentação técnica que fundamente tal atestado. Essa documentação poderá ser solicitada a qualquer tempo pelo Conselho Regional de Psicologia (CRP).

Ainda a respeito dos atestados, um fato que suscita dúvidas diz respeito à aceitação do atestado psicológico nas empresas. Situações, por exemplo, em que o sujeito apresentaria um quadro psicopatológico e, em decorrência disso, justificaria sua ausência e/ou afastamento do traba1ho. Embora a Resolução CFP n ${ }^{\circ}$ 15/1996 admita a possibilidade de emissão de atestado psicológico para afastamento do trabalho, a realidade nos mostra que muitas empresas não o aceitam, exigindo que os mesmos sejam fornecidos por médicos, conforme prevê a CLT (Consolidação das Leis de Trabalho). Em função do CFP legislar somente para a categoria dos psicólogos, as organizações não são obrigadas a aceitarem o atestado psicológico. Por esse motivo, o CFP estuda, juntamente com outros conselhos profissionais, formas de propor um projeto de lei que regulamente $o$ atestado de saúde em substituição ao atestado médico (http://site.cfp.org.br/contato/saude/). Nesse sentido, há jurisprudência que admite a validade dos atestados psicológicos que prescreveram o afastamento do trabalhador. A referida orientação judicial inclusive faz menção à Resolução CFP n ${ }^{\circ} 15 / 1996$, por meio da qual o desembargador reconhece a legitimidade e validade do documento emitido pelo psicólogo (http://www.jusbrasil.com.br/diarios/49485162/ trt-7-10-12-2012-pg-70).

\section{Laudo / Relatório Psicológico}

A Resolução $n^{0}$ 007/2003 do CFP define relatório ou laudo psicológico como "uma apresentação descritiva acerca de situações e/ou condições psicológicas e suas determinações históricas, sociais, políticas e culturais, pesquisadas no processo de avaliação psicológica" (2003b, p. 7). O fato de este tipo de documento ter duas opções de denominação aumenta, em determinadas ocasiões, as dúvidas sobre as especificidades do mesmo.

Em nosso entendimento, as denominações "laudo" e "relatório" não deveriam ser sinônimos. De acordo com o dicionário do Aurélio Online - Dicionário de Português (2008-2016), laudo é "opinião do louvado ou do árbitro", vocábulo que remete, portanto, a um parecer emitido por um especialista. Assim sendo, caberia nos casos de produção de um documento completo, decorrente de processo de avaliação psicológica, como já vem sendo tratado. Por outro lado, a palavra "relatório" remete a algo mais amplo, entendido como "ato de relatar" ou "exposição escrita de fatos". Consequentemente, o termo relatório parece ser mais apropriado a outras situações que não a da avaliação psicológica. Aplicar-se-ia o termo em situações de descrição de evolução de um acompanhamento psicológico, por exemplo, sem o acréscimo de opiniões, julgamentos ou análises, sendo este realizado em instituições ou em consultórios privados. Essa diferenciação entre as nomenclaturas poderia esclarecer dúvidas de muitos profissionais que atuam em diferentes contextos da Psicologia, e não apenas com a avaliação psicológica.

Um aspecto bastante positivo da definição fornecida nessa Resolução é a visibilidade dada ao instrumental técnico variado que pode embasar a avaliação psicológica. "Como todo DOCUMENTO, deve ser subsidiado em dados colhidos e analisados, à luz de um instrumental técnico (entrevistas, dinâmicas, testes psicológicos, observação, exame psíquico, intervenção verbal), consubstanciado em referencial técnico- 
-filosófico e científico adotado pelo psicólogo" (Resolução CFP n 0 007/2003, 2003b, p. 7). Ainda, percebe-se a importância dada ao uso de um referencial técnico-filosófico e científico. Ainda mais relevante em termos éticos é a descrição dada à finalidade do laudo/relatório psicológico, que seria a de "apresentar os procedimentos e conclusões gerados pelo processo da avaliação psicológica, relatando sobre o encaminhamento, as intervenções, o diagnóstico, o prognóstico e evolução do caso, orientação e sugestão de projeto terapêutico, bem como, caso necessário, solicitação de acompanhamento psicológico" (Resolução CFP no 007/2003, 2003b, p. 7).

Contudo, o que se observa na prática é que muitos dos documentos dessa modalidade, possivelmente elaborados por psicólogos sem preparo, resultam em meras descrições de instrumentos aplicados na avaliação, sem preocupação com a coerência entre a demanda, as hipóteses geradas, os procedimentos adotados, as conclusões e os consequentes encaminhamentos. Os prejuízos nessas descrições podem advir de uma má interpretação da orientação do Código de Ética Profissional do Psicólogo (Resolução CFP n ${ }^{\circ}$ 010/2005) o qual afirma que "nos documentos que embasam as atividades em equipe multiprofissional, o psicólogo registrará apenas as informações necessárias para o cumprimento dos objetivos do trabalho" (p. 11) ou mesmo da própria Resolução, que diz que o psicólogo deve limitar-se a fornecer somente as informações necessárias relacionadas à demanda, solicitação ou petição" (p. 7). Isso significa que nos documentos o psicólogo não precisa entrar em detalhes desnecessários ao caso analisado, dados que muitas vezes podem levar a interpretações equivocadas por parte de quem lê assim como expor em demasia o indivíduo avaliado. Talvez fatores como temor exacerbado quanto ao uso que poderá ser feito das informações, bem como uma tendência de omissão no esclarecimento de dados centrais da avaliação, podem gerar laudos/ relatórios psicológicos pouco claros ou inespecíficos, o que pode trazer danos tanto para o avaliado quanto para a imagem do profissional.

No que se refere à estrutura do laudo/relatório, a Resolução exige a apresentação de, no mínimo, cinco itens: identificação, descrição da demanda, procedimento, análise e conclusão. No entanto, não explicita se esses subtítulos são obrigatórios ou se o documento em questão deve apresentar itens que reflitam estes conteúdos, não necessariamente com esta nomenclatura.

Ao examinar cada item separadamente, surgem outras questões não contempladas diretamente pela Resolução. No que se refere ao item Identificação, essa prevê três identificadores: o autor/relator (quem elabora o documento); o interessado (quem o solicita) e o assunto/finalidade (qual a razão/finalidade deste). Em nenhum trecho da Resolução é especificado que dados sobre o avaliado devem constar no documento. Mesmo dentre os identificadores detalhados, a informação central a ser mencionada é o nome do autor/relator e do interessado, não constando dados como formação profissional e vínculo institucional, por exemplo. Temos utilizado, na nossa experiência, os seguintes dados de identificação específicos do(s) avaliado(s): nome completo, data de nascimento, idade, sexo, escolaridade e ocupação e, em casos de criança ou adolescente, os mesmos dados de identificação para os pais.

No identificador Assunto, a Resolução sugere a indicação da razão ou motivo do pedido, e menciona alguns exemplos: "se para acompanhamento psicológico, prorrogação de prazo para acompanhamento ou outras razões pertinentes a uma avaliação psicológica". É relevante observar que, na prática, muitos psicólogos colocam nesse item a informação "para fins de avaliação psicológica", o que na verdade é uma tautologia, uma vez que tanto o atestado como o relatório/laudo psicológico são decorrentes de avaliação psicológica. Sugerimos que o motivo seja descrito de forma específica, por exemplo "para investigação de queixas de memória", "avaliação do funcionamento cognitivo devido a dificuldades escolares", "para avaliação da competência parental para o exercício da guarda".

O segundo item previsto pela estrutura do laudo/relatório é a Descrição da demanda, que é destinada à "narração das informações referentes à problemática apresentada e dos motivos, razões e expectativas que produziram o pedido 
do documento. Nesta parte, deve-se apresentar a análise que se faz da demanda de forma a justificar o procedimento adotado" (Resolução CFP $\mathrm{n}^{\mathrm{o}}$ 007/2003, 2003b, p. 8). Esse item é essencial no que se refere à descrição da(s) queixa(s) relatada(s) pelo solicitante e/ou pelo avaliado e da possibilidade de investigar as causas desta(s) através de uma avaliação psicológica. Em muitos casos, a demanda inicial pode ser mais ampla do que uma avaliação psicológica pode responder, e é responsabilidade do autor do documento explicitar quais aspectos poderão ser avaliados e quais necessitarão, por exemplo, ser encaminhados a outros profissionais para serem melhor investigados.

O terceiro item a constar na estrutura, Procedimento, deve apresentar os recursos e instrumentos técnicos utilizados para coletar as informações (número de encontros, pessoas ouvidas etc.) à luz do referencial teórico-filosófico que os embasa. A Resolução ressalva que o procedimento adotado deve ser pertinente para avaliar a complexidade do que está sendo demandado. Não é especificado se, no caso de uso de instrumentos psicológicos, devem ser apresentadas as referências bibliográficas dos respectivos manuais. Alguns profissionais entendem que o "referencial teórico-filosófico" a que a Resolução se refere implicaria a indicação de somente uma abordagem teórica (psicanálise, cognitivo-comportamental, humanismo, sistêmica, gestáltica) utilizada para a avaliação. No nosso entendimento, quem trabalha com avaliação psicológica pode utilizar diferentes referenciais e, inclusive, integrá-los para o entendimento dinâmico do avaliado. Por exemplo, quem trabalha com avaliação pode utilizar técnicas projetivas, com enfoque psicanalítico, assim como avaliar aspectos cognitivos utilizando o Wechsler Intelligence Scale for Children (WISC IV), aprofundando entendimentos de uma linha mais cognitiva. Nesse sentido, ele vai se utilizar de diferentes abordagens teóricas. Na realidade, este é o diferencial do psicólogo que trabalha com avaliação psicológica: ter uma visão integrada do avaliado, devendo inclusive se utilizar de conhecimentos que extrapolam a Psicologia (por exemplo, noções de neurologia, fonoaudiologia e fisiologia).
O item Análise corresponde à exposição descritiva metódica, objetiva e fiel dos dados colhidos e das situações vividas relacionados à demanda em sua complexidade. É dado destaque à necessidade de a avaliação psicológica considerar as determinações históricas, sociais, econômicas e políticas das questões de ordem psicológica. Tal advertência é relevante na medida em que orienta que a avaliação psicológica não deve servir como mera ferramenta de reprodução de práticas estigmatizantes sem reflexão. Contudo, o termo Análise não se mostra adequado, uma vez que pressupõe inferência e interpretação, no entanto, as orientações dadas para esse item sugerem uma exposição descritiva relacionada à demanda. $\mathrm{O}$ item se torna confuso, pois pressupõe a inclusão simultânea de uma descrição (que poderia ser compreendida como a história do caso), da apresentação dos resultados e do estabelecimento de suas relações com os dados colhidos.

Como alternativa ao item Análise, sugerimos sua substituição por três itens, conforme descreveremos a seguir. O primeiro seria um item específico para a descrição da história da pessoa avaliada, desvinculada da interpretação feita pelo psicólogo acerca desses eventos, bem como a impressão geral transmitida pelo paciente ao autor (Pasquali, 2001). A nomenclatura utilizada nesse item pode variar conforme a demanda da avaliação (ex.: História Clínica, Histórico Familiar, Histórico Ocupacional, etc.). O segundo seria denominado Resultados, contendo dados obtidos a partir dos procedimentos utilizados. O terceiro item, Integração dos Dados, promoveria a síntese e a interpretação entre todos os dados obtidos durante a avaliação. Em determinadas situações, esses dois últimos itens podem ser apresentados em conjunto.

O item Conclusão contempla a exposição do resultado e/ou considerações a respeito da investigação a partir das referências que subsidiaram a avaliação. A Resolução ressalta também a importância de sugestões e projetos de trabalho que contemplem a complexidade das variáveis envolvidas durante o processo.

Como orientações gerais para a escrita deste tipo de documento, baseadas em dificuldades 
frequentemente apresentadas por psicólogos e estudantes de Psicologia, destacamos: (a) a importância da escolha ética das informações a serem apresentadas, considerando a quem o documento será destinado, (b) a necessidade de uma escrita descritiva da demanda e da história clínica, evitando julgamentos ou interpretações, (c) a apresentação clara dos procedimentos adotados e dos resultados obtidos, considerando o destinatário do documento e (d) o comprometimento do autor do laudo com o encaminhamento do caso avaliado.

No que se refere ao primeiro ponto, salientamos que a escolha das informações a serem relatadas deve ser norteada pela análise da demanda feita inicialmente no processo de avaliação psicológica. O conteúdo e o nível de complexidade da linguagem (mais simples e direta ou mais técnica e detalhada) a serem utilizados no documento estão diretamente relacionados à definição das questões a serem investigadas pela avaliação e do destinatário do documento (que pode ser tanto um profissional, geralmente da área da saúde, como o próprio paciente ou responsável). Reforça-se também a importância de uma escrita concisa, na qual não é necessário relatar cada encontro ou procedimento feito com o paciente, mas sim as informações mais relevantes para a compreensão da problemática do caso, como eventos e conteúdos que se repetem com frequência na história daquele, assim como fatos incomuns, mas marcantes em sua trajetória.

O segundo ponto aborda a importância da descrição da demanda e da história clínica do avaliado de forma não interpretativa. Observa-se que muitas vezes os autores dos documentos psicológicos têm dificuldade em relatar de forma objetiva (conforme relato feito pelo avaliado, familiar ou profissional envolvido) as queixas e a história do caso. É importante que esta parte do documento deixe explícito quem é a fonte de cada informação, além de mencionar os valores atribuídos a estas informações pelos envolvidos, sem interferência da leitura feita pelo avaliador. Tal descrição permite que os futuros destinatários do documento (frequentemente profissionais aos quais o paciente foi encaminhado) compreendam melhor o caso e a investigação que foi feita a partir da demanda inicial e da história do avaliado. Ressalta-se também a importância de organizar as informações de forma que essa seja compreensível, respeitando a ordem cronológica dos acontecimentos e separando os parágrafos com base em conteúdos comuns (p.ex.: desenvolvimento inicial, período escolar, relacionamento familiar, relacionamento social, etc.).

Cabe fazer uma observação, no contexto do relato da demanda e da história clínica, sobre o uso do termo "sic". Muitas vezes esse é utilizado como sigla para "segundo informações colhidas". No entanto, trata-se de uma contração de um termo do latim, "sicut", que significa "assim, desse modo" (Maia \& Palomo, 2012). O Dicionário Houaiss da Língua Portuguesa define que sic, utilizado entre parênteses ou colchetes em uma citação, indica que o texto está sendo reproduzido exatamente da mesma forma como no original, por errado ou estranho que esse possa parecer (Houaiss \& Villar, 2001). Ressalta-se que o simples uso de aspas na afirmativa do paciente já demonstra tratar-se de uma transcrição literal, tornando desnecessário o uso do sic como popularmente utilizado (no sentido de "segundo informações colhidas"). Sugerimos que o uso do termo sic seja limitado a situações nas quais não se pode confirmar a veracidade ou acurácia do relato ou nas quais se deseje destacar uma informação ou incongruência, evitando um uso que implicitamente desqualifica o relato original. A seguir, um exemplo no qual seria recomendado o uso do termo sic: "o paciente afirma que nunca viu o pai 'alto'(sic) - ou seja, alcoolizado". Trechos do relato em que se apresente o discurso direto do paciente não necessitariam de sic, apenas de aspas.

A apresentação clara dos procedimentos e resultados da avaliação, incluída no terceiro ponto, tem como eixo central o tipo de destinatário a quem este documento se destina. Nesse caso, cabe fazer uma diferenciação entre: destinatários leigos, profissionais da área da saúde não psicólogos e psicólogos. No caso dos destinatários leigos, a descrição dos procedimentos e resultados deve ser clara e específica, mas sem o uso de termos excessivamente técnicos (ou, no caso de serem usados, estes devem vir seguidos de uma 
explicação em linguagem simples). Sugere-se também que seja evitado o uso da exposição de resultados numéricos sem a devida interpretação (por exemplo, o que significa o percentil obtido pelo paciente). No caso de documentos destinados a profissionais da área da saúde não psicólogos, a terminologia técnica pode ser utilizada, mas é contraindicado o uso de jargões psicológicos. No que tange aos destinatários psicólogos, é importante lembrar que nem todos os profissionais da área têm conhecimentos específicos de avaliação psicológica, portanto se faz necessário o esclarecimento de termos da área.

Por fim, no último ponto, ressaltamos a importância de que o documento produzido seja coerente em seu propósito. Se a avaliação foi solicitada para a investigação de um problema psicológico, a conclusão do documento deve retomar os aspectos principais do processo, bem como sugerir indicações terapêuticas para esta demanda. Não é imprescindível indicar profissionais específicos, mas é essencial ao menos sugerir tratamentos, condutas e outros tipos de investigações, quando o caso necessitar. Em algumas situações, também pode ser preciso explicitar os riscos que a manutenção de um determinado estado, sem auxílio terapêutico, pode implicar.

\section{Parecer}

O Parecer Psicológico é definido pela Resolução CFP n $n^{\circ}$ 007/2003 como "um documento fundamentado e resumido sobre uma questão focal do campo psicológico cujo resultado pode ser indicativo ou conclusivo" (2003b, p. 9). Explica, ainda, que esse documento tem como objetivo

apresentar resposta esclarecedora, no campo do conhecimento psicológico, através de uma avaliação especializada, de uma 'questão-problema', visando a dirimir dúvidas que estão interferindo na decisão, sendo, portanto, uma resposta a uma consulta, que exige de quem responde competência no assunto. (2003b, p. 9)

Aqui cabe retomar a observação da Resolução ${ }^{\circ}$ 007/2003 (2003b) sobre o fato de o parecer não ser um documento decorrente de avaliação psicológica. Seu objetivo é diferente do laudo/ relatório e, portanto, sua estrutura é mais objetiva, dispensando o item "procedimentos". Trata-se de uma resposta pontual e esclarecedora, que exige conhecimento da ciência psicológica. Pareceres podem ser solicitados por instituições (como escolas), ou profissionais (psiquiatras, neurologistas, fonoaudiólogos, advogados). A resposta a essas solicitações não exige a necessidade de realizar uma avaliação psicológica, pois o psicólogo responderá ao que lhe foi questionado a partir de seu conhecimento técnico e também embasado em referencial teórico pertinente. Um advogado pode, por exemplo, solicitar um parecer psicológico acerca dos possíveis benefícios e malefícios da guarda compartilhada para crianças com menos de dois anos de idade. $\mathrm{Na}$ área clínica, um psicólogo pode ser solicitado a realizar um parecer sobre a possibilidade de uma criança com Transtorno do Espectro Autista acompanhar uma classe regular de primeiro ano do ensino fundamental. Nessas situações, o psicólogo não responderia com base em um único sujeito, mas considerando o atual estado da arte que motivou tal consulta.

A Resolução CFP nº 007/2003 (2003b) faz referência também à possibilidade da existência de quesitos, os quais são perguntas elaboradas pelo solicitante da avaliação. Sempre que existirem quesitos, o parecerista deverá respondê-los de forma sintética e convincente, não deixando nenhum quesito sem resposta. Nas situações em que não existam dados suficientes para emitir uma resposta mais categórica, deve-se utilizar a expressão "sem elementos de convicção". Se o quesito estiver mal formulado, pode-se afirmar "prejudicado", "sem elementos" ou "aguarda evolução". Porém, é importante reforçar que todos os quesitos exigem uma resposta.

No que tange aos quesitos, cabe aqui uma observação importante. Embora a definição de quesito remeta a "uma questão sobre a qual se espera uma resposta ou esclarecimento", em nossa prática observamos ser incomum a solicitação de respostas a quesitos em outras áreas que não a jurídica. É comum que profissionais de áreas da saúde, como médicos e fonoaudiólogos, encaminhem questões pontuais para serem 
respondidas pelos profissionais; contudo, esses questionamentos não costumam ser identificados como quesitos. Por outro lado, nas avaliações encaminhadas pelo Poder Judiciário, esse termo é bastante frequente, com a presença de quesitos elaborados tanto pelo Juiz de Direito, quanto pelo Promotor de Justiça e/ou pelos advogados das partes. Nesse ponto, temos uma crítica relevante para apontar referente à divergência de nomenclaturas entre a Resolução do CFP e o que está disposto no Código de Processo Civil (CPC).

De acordo com a definição de parecer da Resolução do CFP, poderia se interpretar que os peritos emitiriam um parecer, visto ser este um "documento fundamentado e resumido sobre uma questão focal do campo psicológico cujo resultado pode ser indicativo ou conclusivo". Responderiam, também, aos quesitos apresentados pelas partes. Outra Resolução do CFP que corrobora essa divergência de nomenclaturas é a Resolução $n^{\circ} 17 / 2012$, que dispõe sobre a atuação do psicólogo como perito nos diversos contextos. Em seu artigo $8^{\circ}$, há a orientação de que "em seu parecer, o psicólogo perito apresentará indicativos pertinentes à sua investigação .

. .”. Entendemos que a definição de parecer da Resolução CFP nº 007/2003 (2003b) gera dúvidas e confusões quando essa demanda advém do Poder Judiciário, cujas legislações preveem a denominação de laudo para o documento produzido por peritos, e de parecer para o documento emitido pelos assistentes técnicos.

Após a apresentação das críticas em relação à nomenclatura do documento, explorar-se-á a partir de agora a estrutura do parecer. Conforme disposto na Resolução CFP n ${ }^{\circ}$ 007/2003 (2003b), quatro itens compõem o parecer: identificação, exposição de motivos, análise e conclusão. Em relação à Identificação, diferentemente do laudo, há a orientação de indicar a titulação do parecerista, assim como a titulação de quem está solicitando. Entende-se que essa orientação seja no sentido de reforçar a especialidade do psicólogo a quem foi encaminhada a demanda do parecer, justificando sua competência para tratar do assunto.

No item "exposição de motivos", deve constar o objetivo da consulta e dos quesitos ou dúvi- das do solicitante. A Resolução deixa claro que não há necessidade de descrever detalhadamente os procedimentos, dados colhidos ou até mesmo o nome dos envolvidos. Complementando a crítica feita anteriormente em relação à diferença de nomenclaturas entre as áreas da Psicologia e do Direito, cabe observar que o perito, ao elaborar seu laudo, apresenta a "resposta aos quesitos" como um novo item, após a "conclusão", antes de datar e assinar o documento (Rovinski, 2004). A Resolução do CFP não deixa clara essa informação; pelo contrário, entende-se que os quesitos deveriam constar no item "exposição de motivos", o que seria uma prática inadequada no contexto forense.

A análise deve responder à demanda descrita no item "exposição de motivos", de uma forma resumida, com base no corpo conceitual da ciência psicológica. Pode, ainda, incluir referências de trabalhos científicos para citações e informações. Diferentemente da discussão proposta na estrutura do Laudo/Relatório acerca do termo Análise, aqui entendemos que o termo mostra-se adequado.

Por fim, a conclusão apresentará o posicionamento do parecerista, que deverá responder à questão levantada. A conclusão deve ser objetiva e concisa, pois se espera que a discussão dos dados levantados conste no item "análise", ou seja, a justificativa da conclusão estaria apresentada no item anterior. E, como em todos os documentos psicológicos, ao final deverá ser informada data e local, e deverão constar a assinatura do psicólogo e seu carimbo, com número do registro profissional. No caso de documentos com mais de uma página, o psicólogo deverá rubricar todas as folhas do documento (a numeração das páginas não é obrigatória, mas indicada).

\section{Validade e Guarda dos Documentos}

Os últimos itens contemplados pela Resolução CFP no 007/2003 (2003b) dizem respeito à "validade dos conteúdos dos documentos" e "guarda dos documentos e condições de guarda". Em relação ao prazo de validade, a Resolução orienta que o psicólogo deverá considerar a legislação vigente nos casos já definidos. Em 
não havendo definição legal, o psicólogo poderá indicar, sempre que possível, o prazo da validade do conteúdo no próprio documento, dispondo dos fundamentos para tal indicação. A título de exemplo, cita-se o caso de uma paciente que se submeteu à avaliação neuropsicológica e, paralelamente, estava passando por processo de desintoxicação por agentes químicos. Foi sugerido no laudo decorrente da avaliação que, após um ano, a avaliação fosse refeita, a fim de comparar os resultados, com o objetivo de verificar a incidência de progressos ou prejuízos na área da cognição, considerando os possíveis efeitos do tratamento de desintoxicação.

No que tange à guarda dos documentos, a Resolução indica o prazo mínimo de cinco anos para a guarda não apenas do laudo, mas de todos os materiais referentes à avaliação. Neste caso, orientamos que se incluam anotações do psicólogo, folhas de resposta dos testes e outros materiais que fundamentem os achados da avaliação. A guarda é de responsabilidade do psicólogo ou da instituição em que a avaliação foi realizada. Poderá haver ampliação desse prazo nos casos previstos em lei. Por fim, caso haja a extinção do Serviço de Psicologia, deverão ser seguidas as orientações do Código de Ética para o destino dos documentos.

\section{Orientações Práticas para a Escrita de Documentos}

Considerando nossa experiência enquanto supervisoras de avaliação psicológica, foi possível observar a dificuldade que muitos estudantes e/ou profissionais da Psicologia apresentam para redigir seus documentos. No intuito de contribuir para esse aprimoramento da escrita, exemplificaremos algumas falhas encontradas em documentos, justificando sua inadequação, a fim de que aqueles que buscam orientações de redação possam, ao menos, evitar incorrer em tais erros.

\section{Utilização de Linguagem Não-Técnica}

"E de repente, surge aquele estranho querendo abusá-la a atacando-a da forma mais cruel que uma criança pode conceber ... Essa paciente está muito sentida, com aqueles soluços que parecem do fundo de sua alma infantil". "Joana é uma mulher guerreira e muito sofredora".

Os trechos acima, extraídos de documentos emitidos por psicólogos, demonstram a ausência de linguagem técnica e incorrem na emissão de julgamentos morais. Parecem, inclusive, remeter a uma linguagem de texto dramático e/ou romântico. Nesses casos, termos como "a paciente apresenta grave sofrimento psíquico" e "revela persistência diante de seus objetivos" são sugestões que apresentam uma linguagem técnica mais adequada.

\section{Afirmações Categóricas}

"A partir das entrevistas realizadas com mãe, pai, filha, avós e tia materna da vítima, $\underline{e}$ possivel afirmar, com certeza, que abusos sexuais e fisicos ocorreram".

Ainda que o psicólogo possa estar convencido da possível ocorrência de abusos sexuais e físicos, a redação de seu documento deve ser mais cautelosa. A Psicologia não é uma ciência que nos permita certezas absolutas, especialmente por meio de dados coletados exclusivamente a partir de entrevistas. Nesse caso, o profissional poderia ter usado alguma expressão do tipo "é possível evidenciar a existência de fortes indícios de ocorrência de abusos sexuais e físicos". Nessa situação, é importante que o profissional descreva, ainda, quais são esses indícios, preferencialmente relacionando o observado com referências da literatura que corroborem seus achados clínicos. Tais referências podem constar como nota de rodapé ou, ainda, em uma lista ao final do documento.

\section{Informação Imprecisa, Sem Fundamentação Técnico-Científica}

"Sr. João demonstra um comportamento extremamente agressivo e, sem que haja mínimos critérios de segurança, quanto à doença mental/neurológica que acomete o Sr. João e que se apresenta como grave, seu contato com a filha não deve ser permitido, para segurança desta."

Os profissionais que emitiram o documento cujo trecho foi extraído acima fazem referência 
a uma "doença mental/neurológica", descrita como grave. Entretanto, não há identificação de que doença seria, nem tampouco embasamento para justificar os critérios diagnósticos utilizados para chegar a tal conclusão. Quando houver um diagnóstico do paciente sob avaliação, é importante deixar claro qual o diagnóstico (informando, inclusive, o CID) e, ainda, descrever os critérios que permitiram a conclusão por tal diagnóstico. Esse apontamento é especialmente importante para o próprio autor do documento, como um respaldo da qualidade técnica de seu trabalho.

\section{Desrespeito aos Limites de Atuação do Psicólogo}

"Foi ordenado a Srta. Maria que não permitisse o contato de sua filha com o pai".

É preciso atentar aos limites de nossa atuação e, para tanto, tomar cuidado com a utilização de certas palavras. Enquanto psicólogos, ainda que exercendo o papel de peritos, por exemplo, não temos autoridade para "ordenar", o que seria da competência do juiz, se aplicável ao caso. Ao psicólogo compete "recomendar", "sugerir", "indicar".

\section{Pessoalidade na Escrita}

"A seguir apresentamos análise de cada um dos avaliados".

"Nessa ocasião o avô compartilhou conosco a perda da esposa e sua preocupação com os netos".

Os documentos devem primar pela impessoalidade na escrita, evitando ao máximo a utilização de linguagem em primeira pessoa, como no exemplo acima. Para evitar esse erro, sugere-se a utilização de escrita na voz passiva (serão apresentados), ou reflexiva (apresentar-se-á). No segundo exemplo, o trecho sublinhado poderia ser substituído por "informou”.

\section{Uso de Gíria, Expressão Coloquial ou Depreciação}

"Joana apresentava-se vestida de acordo com a idade, mas sem grandes investimentos no vestuário".
"O paciente teve a oportunidade de conviver com seus pais casados por somente três anos . . . Ele cursou a faculdade por cinco anos e, durante todo esse tempo, não conseguiu avançar além do terceiro semestre".

No primeiro exemplo citado, o trecho sublinhado faz uso de gíria ou expressões coloquiais desnecessárias ao entendimento da situação. Já no último exemplo, fica implícita a avaliação negativa que o autor faz sobre a duração do casamento dos pais do avaliando ou o desempenho deste na faculdade. O psicólogo deve se ater a relatar fatos ou, quando necessário, se limitar a reproduzir juízos de valor expressados pelo avaliando ou por pessoas envolvidas no caso por meio de aspas, nunca expondo opiniões pessoais acerca da vida do sujeito.

\section{Uso de Termos Técnicos Desnecessários ou Sem a Devida Explicação}

"Essa escala demonstrou que o paciente encontra-se num nivel intelectual superior, com alta capacidade de análise e síntese, bem como de insight. . . . Suas fraquezas estão centradas numa dificuldade especifica de atenção e de memória imediata, o que sugere uma baixa capacidade do ego sobre os processos de pensamento."

"Nesse instrumento foi detectada uma tendência do indivíduo de utilizar em demasia a fantasia, gerando uma forma de pensamento infantil e egocêntrica".

Em alguns casos, como no primeiro exemplo, o termo técnico pode ser utilizado, desde que acompanhado de um esclarecimento em linguagem acessível. No outro exemplo, a reescrita do trecho sublinhado seria indicada, evitando a possibilidade de uma interpretação inadequada.

\section{Uso Inadequado de Informações Obtidas por Meio de Técnicas Psicológicas}

"No teste HTP, onde o paciente deve desenhar uma casa, uma árvore e uma pessoa em folhas individuais, tanto colorido como posteriormente, sem cor". 
"Na escala SNAP, das 26 questões da escala, as respostas da mãe foram, 15 'bastante', 8 'demais', 2 'um pouco' e 1 'nada'. As respostas da professora não foram muito diferentes: 17 'bastante', 6'demais' e 3 'um pouco"'.

"A análise das características de personalidade de Maria sugere que ela não dispõe de recursos psicológicos suficientes para enfrentar seus disparadores internos de tensão. Os dados indicaram que a paciente apresenta um estilo vivencial do tipo ambigual, isto é, seu estilo de responder as demandas do meio ocorrem tanto por meio de atividades reflexivas (pensamento), bem como por meio dos afetos eliciados (emoção)."

Os dois exemplos iniciais apresentam descrições excessivas das técnicas utilizadas, sem benefício para a compreensão do desempenho do avaliado ou da responsável. O terceiro exemplo apresenta uma interpretação que utiliza muitos termos específicos da literatura das técnicas projetivas que não contribuem para a clara explicação dos fenômenos observados.

\section{Considerações Finais}

O presente artigo buscou apresentar comentários e críticas à Resolução CFP n ${ }^{\circ}$ 007/2003 (2003b), almejando contribuir para o aprimoramento dos documentos psicológicos produzidos. Vários apontamentos feitos ao longo do texto são decorrentes de discussões em sala de aula e/ou de supervisões e que não estavam formalizadas em um material de referência. Esperamos que este artigo possa ser utilizado como um recurso didático, fomentando novas discussões e contribuindo para a formação dos psicólogos. Além disso, desejamos que aqueles profissionais que trabalham com avaliação psicológica possam se beneficiar das informações aqui dispostas como uma fonte de esclarecimentos.

A produção escrita de documentos deixa evidente a quantidade de conhecimentos específicos necessários para o trabalho com avaliação psicológica. Entendemos que a formação básica em Psicologia não é suficiente para dar conta desse conhecimento e realizar uma avaliação de qualidade, produzindo um laudo com compe- tência. Por isso, a formação continuada após a graduação, como a especialização em Avaliação Psicológica, deveria ser uma exigência do Conselho Federal de Psicologia para aqueles que gostariam de atuar nessa área. Nesse sentido, defendemos a criação do título de Especialista em Avaliação Psicológica.

Por fim, vale destacar que os documentos, em especial, laudo e parecer, são um dos meios pelos quais o psicólogo se comunica com pessoas leigas ou profissionais de outras áreas do conhecimento e, portanto, esses registros representam a sua competência profissional. Essa expressão de competência engloba a seleção dos dados que serão expostos nos documentos psicológicos. Percebe-se, então, a responsabilidade que o psicólogo possui ao produzir esses documentos, já que precisa entender até que ponto oferece benefícios ou mesmo riscos para seu cliente/paciente, ao destinatário e a si próprio.

\section{Referências}

American Psychological Association. (2002). Ethical principles of psychologists and Code of Conduct. Retrieved from http://www.apa.org/ethics/ code/index.aspx

Capellini, S. A., Oliveira, A. M., \& Cuetos, F. (2010). PROLEC: Provas de avaliação dos processos de leitura. São Paulo, SP: Casa do Psicólogo.

Cruz, R. M. (2002). Perícia em Psicologia e laudo. In R. M. Cruz, J. C. Alchieri, \& J. J. Sardá Jr. (Eds.), Avaliação e medidas psicológicas: Produção do conhecimento e da intervenção profissional (pp. 263-274). São Paulo, SP: Casa do Psicólogo.

Cunha, J. A. (2000). Passos do Processo Psicodiagnóstico. In J. A. Cunha (Ed.), Psicodiagnóstico - V (pp. 105-140). Porto Alegre, RS: Artmed.

Del-Ben, C. M., Vilela, J. A. A., Crippa, J. A. S., Hallak, J. E. C., Labate, C. M., \& Zuardi, A. W. (2001). Confiabilidade da "Entrevista Clínica Estruturada para o DSM-IV - Versão Clínica" traduzida para o português. Revista Brasileira de Psiquiatria, 23(3), 156-159. doi:10.1590/ S1516-44462001000300008

Dicionário do Aurélio Online - Dicionário de Português. (2008-2016). Laudo. Copyright 2008-2016 de Dicionário do Aurélio Online - Dicionário de 
Português. Recuperado em https://dicionariodoaurelio.com/laudo

Dicionário do Aurélio Online - Dicionário de Português. (2008-2016). Relatório. Copyright 2008-2016 de Dicionário do Aurélio Online Dicionário de Português. Recuperado em https:// dicionariodoaurelio.com/relatorio

Folstein, M. F. \& Folstein, S. E., \& McHugh, P. R. (1975). "Mini-mental state": A practical method for grading the cognitive state of patients for the clinician. Journal of Psychiatric Research, 12, 189-198. doi:10.1016/0022-3956(75)90026-6

Frizzo, N. P. (2004). Infrações éticas, formação e exercício profissional em Psicologia (Dissertação de mestrado, Programa de Pós-Graduação em Psicologia, Centro de Filosofia e Ciências Humanas, Universidade Federal de Santa Catarina, Florianópolis, SC, Brasil).

Houaiss, A., \& Villar, M. S. (2001). Dicionário Houaiss da Língua Portuguesa. Rio de Janeiro, RJ: Objetiva.

Hutz, C. S. (2009). Ética na avaliação psicológica. In C. S. Hutz (Ed.), Avanços e polêmicas em avaliação psicológica (pp. 297-310). São Paulo, SP: Casa do Psicólogo.

Lago, V. M., \& Bandeira, D. R. (2013). Sistema de Avaliação do Relacionamento Parental: SARP Manual técnico. São Paulo, SP: Casa do Psicólogo.

Maia, J. A., \& Palomo, L. M. (2012). "SIC”. Revista da Associação Médica Brasileira, 58(1), 8-9.

Pasquali, L. (2001). Técnicas de exame psicológico (TEP) - Manual: Vol. I. Fundamentos das técnicas psicológicas. São Paulo, SP: Casa do Psicólogo.

Resolução CFP no 15/1996. (1996). Brasília, DF: Conselho Federal de Psicologia. Recuperado em http://site.cfp.org.br/wp-content/uploads/ 1996/12/resolucao1996_15.pdf

Resolução CFP n ${ }^{\circ}$ 30/2001. (2001). Brasília, DF: Conselho Federal de Psicologia. Recuperado em http://site.cfp.org.br/wp-content/uploads/ 2001/12/resolucao2001_30.pdf

Resolução CFP n ${ }^{\circ}$ 17/2002. (2002). Brasília, DF: Conselho Federal de Psicologia. Recuperado em http://site.cfp.org.br/wp-content/uploads/ 2002/12/resolucao2002 17.PDF

Resolução CFP no 002/2003. (2003a). Brasília, DF: Conselho Federal de Psicologia. Recuperado em http://site.cfp.org.br/wp-content/uploads/ 2003/03/resolucao2003_02_Anexo.pdf
Resolução CFP no 007/2003. (2003b). Brasília, DF: Conselho Federal de Psicologia. Recuperado em http://site.cfp.org.br/wp-content/uploads/ 2003/06/resolucao2003_7.pdf

Resolução CFP no 010/2005. (2005). Aprova o Código de Ética Profissional do Psicólogo. Brasília, DF: Conselho Federal de Psicologia. Recuperado em http://site.cfp.org.br/wp-content/uploads/ 2005/07/resolucao2005_10.pdf

Resolução CFP no 001/2009. (2009). Brasília, DF: Conselho Federal de Psicologia. Recuperado em http://site.cfp.org.br/wp-content/uploads/ 2009/04/resolucao2009_01.pdf

Rovinski, S. L. R. (2004). Fundamentos da Perícia Psicológica Forense. São Paulo, SP: Vetor.

Shine, S. K. (2009). Andando no fio da navalha: Riscos e armadilhas na confecção de laudos psicológicos para a justiça (Tese de doutorado não publicada, Instituto de Psicologia da Universidade de São Paulo, SP, Brasil).

Silva, D. M. P. (2006). O Laudo Pericial. In D. M. P. Silva, Psicologia Jurídica no Processo Civil Brasileiro (pp. 183-206). São Paulo, SP: Casa do Psicólogo.

Stein, L. M. (1994). TDE: Teste de Desempenho Escolar: Manual para aplicação e interpretação. São Paulo, SP: Casa do Psicólogo.

Tavares, M. (2012). Considerações preliminares à condução de uma Avaliação Psicológica. Avaliação Psicológica, 11(3), 321-334.

The National Commission for the Protection of Human Subjects of Biomedical and Behavioral Research. (1979). The Belmont Report: Ethical principles and guidelines for the protection of human subjects of research (DHEW Publication No.78-0012). Washington, DC: Department of Health, Education, and Welfare. Retrieved from http:/www.hhs.gov/ohrp/humansubjects/ guidance/belmont.html 